\title{
ARTIGOS
}

\section{PREVALÊNCIA DA INFECÇÃO PELO VÍRUS B NA COMUNIDADE HOSPITALAR}

\author{
Henrique Sergio Moraes Coelho, Sofia Regina Teixeira Artemenko, \\ Carmen Nogueira Martins, Diana Maul de Carvalho, Joaquim Valente, \\ Eloisa Costa Rodrigues, Lilian dos Santos Alves e Maria Luiza de Matos Martins.
}

\begin{abstract}
Estudou-se a prevalência de marcadores para a hepatite B (HBsAg, AntiHBc e AntiHBs) em profissionais de saúde, a fim de identificar grupos de maior risco onde estaria indicada a vacinação pré-exposição. Comparando-os com os funcionários administrativos do mesmo hospital, observamos índices significativamente superiores em grupos como cirurgiões $(40,0 \%)$ e profissionais de hemodiálise $(36,4 \%)$, que apresentaram taxas de ferimentos no trabalho, de, respectivamente, $93,3 \%$ e 77,3\%. Outros grupos mostraram grande aumento da prevalência em função do maior tempo de atuação profissional, comprovando seu risco. Outras formas de transmissão, como transfusão e contato íntimo com portadores de hapatite, não tiveram significância. Os autores concluiram que a vacinação está indicada em cirurgiões e profissionais de hemodiálise, bem como dentistas e técnicos de laboratório.
\end{abstract}

Palavras-chaves: Hepatite B. Profissionais de saúde.

A hepatite B é uma infecção cosmopolita, estimando-se em cerca de duzentos milhões o número de infectados com este virus ${ }^{7}$.

Descrita inicialmente como hepatite por, soro homólogo, era sua transmissão creditada a transfusões sangüíneas ou contaminação com sangue infectado de material hospitalar (injeções e vacinas) ${ }^{14} 16$. Nos últimos anos, tem-se observado uma modificação nos aspectos epidemiológicos da doença, visto que, com a descoberta dos marcadores sorológicos da hepatite $\mathbf{B}$, pode-se controlar a transmissão pela administração de sangue e conhecer melhor determinados grupos de risco. 1921

Assim, hoje são considerados como potencialmente capazes de adquirir a infecção, e por conseguinte disseminá-la, os filhos de mães portadoras do virus $\mathrm{B}$, os homossexuais, os viciados em drogas endovenosas e os profissionais de saúde. 1918

Diversos estudos ${ }^{3} 15$ têm retratado uma maior prevalência de marcadores da infecção pelo virus B entre profissionais de saúde, bem como uma incidên-

Trabalho realizado nos Serviços de Clínica Médica, Hemoterapia e Medicina Preventiva, Hospital Universitário Clementino Fraga Filho, Universidade Federal do Rio de Janeiro.

Endereço para correspondência: Dra. Sofia Regina T. Artemenko. Caixa Postal 1818, 20001 Rio de Janeiro, RJ, Brasil.

Recebido para publicação em 04/06/90. cia de hepatite aguda maior do que na população em geral. Por este motivo, resolvemos estudar a prevalência de infecção presente e passada pelo virus B entre os profissionais de saúde de um hospital universitário, que têm em comum o fato de se exporem, por força de sua atividade profissional a um fator de risco (sangue $e$ material contaminado com o mesmo), comparando-os a um grupo de funcionários administrativos do mesmo hospital, que serviram como controle.

Procuramos também correlacionar a especialidade exercida, a idade e o tempo de ocupação com a prevalência.

\section{MATERIAL E MÉTODOS}

Foram estudados, no periodo de julho de 1987 a novembro de 1989, 292 individuos divididos em dois grupos, em função da atuação ou não com materiais contaminados com sangue e/ou derivados (o mecanismo de maior relevância na transmissão da hepatite $B$ aos profissionais de saúde).

Os grupos foram assim definidos:

Grupo 1. Grupo de risco constituido por 142 profissionais do hospital exercendo uma das seguintes funções: médicos cirurgiōes (30), cirurgiões dentistas (30), enfermeiro ou auxiliar de enfermagem (30), hemoterapeutas e técnicos de laboratório de hematologia (30) e profissionais de hemodiálise (22).

Grupo 2. Grupo controle, constituído de 150 pessoas que exercem apenas funções administrativas (técnicos 
Coelho HSM, Artemenko SRT, Martins CN, Carvalho DM, Valente J, Rodrigues EC, Alves LS, Martins MLM. Prevalência da infecção pelo vírus B na comunidade hospitalar. Revista da Sociedade Brasileira de Medicina Tropical 23:71-76, abr-jun, 1990

de administração, secretários, etc.); representa nosso grupo não exposto ao fator de risco.

Os dois grupos foram submetidos a três fases do trabalho, quais sejam:

Fase 1. Aplicação de um questionário efetuado pelos estudantes, no qual se procurou estabelecer o grau de exposição a fatores de risco e a história epidemiológica dos individuos.

Procuramos determinar a presença de contato com o fator de risco, por quaisquer meios, dentro do grupo controle (por exemplo, um agente administrativo que já tivesse atuado como técnico de laboratório), bem como o exercício de função de subgrupos diferentes dentre os subgrupos de risco. Pesquisamos também a presença de outros fatores de risco para hepatite $\mathrm{B}$ não relacionados à atividade profissional, como história de hemotransfusão, uso de droga endovenosa, contato sexual com parceiros sabidamente infectados.

Pesquisamos a doação de sangue com fins preventivos futuros, no intuito de esclarecer os infectados quanto à contra-indicação do hábito, embora não possamos explicar com os conhecimentos atuais a presença de diferenças na prevalência de marcadores virais entre a população normal e doadores, observada em diversas estatísticas 820 .

A vacinação prévia foi pesquisada em função de sua forte possibilidade, por se tratar de ambiente universitário, e para justificar o encontro de AntiHBs isolado no soro.

As perguntas que se seguem ao questionário principal foram dirigidas ao grupo de técnicos de laboratório a fim de identificar o nivel de cuidados dispensados durante o trabalho, com fins educativos. Fase 2. Coleta de amostra de sangue $(10 \mathrm{ml})$, pelo sistema a vácuo (Vacutainer), sendo o soro estocado em resfriamento para pesquisa posterior da presença dos seguintes marcadores virais: $\mathrm{HBsAg}$, AntiHBs e AntiHBc.

Foi utilizado o teste ELISA do laboratório Abbot. Seu critério de positividade é baseado na faixa de segurança do cut off, que é um valor limite calculado a partir de resultados obtidos de amostras positivas e negativas predeterminadas e que correm em paralelo ao estudo dos soros.

Fase 3. Por fim, todos os resultados foram submetidos à análise estatística através da comparação de proporções, utilizando-se o teste do $\mathrm{X}^{2}$ tendo sido considerados estatisticamente significativos quando o valor de $\mathrm{p}$ $<0,05$

\section{RESULTADOS}

Estudamos 292 individuos com idade variando de 19 a 75 anos, com médias aproximadamente iguais nos dois grupos, quando avaliamos os dados contidos no questionário (Tabela 1).

Tabeia 1 - Distribuição dos parâmetros pesquisados por grupos Controle e de Risco.

\begin{tabular}{lcc}
\hline \multicolumn{1}{c}{ Parâmetros } & Controle & Risco \\
\hline Idade média (anos) & 37,6 & 36,5 \\
Sexo masculino & $46,0 \%(69)$ & $48,5 \%(69)$ \\
Inf. acumul. virus B & $17,3 \%(26)$ & $26,8 \%(38)^{*}$ \\
Tempo ocupação (méd) & 7,5 anos & 7,8 anos \\
História passada hepatite & $4,7 \%(07)$ & $14,8 \%(21)^{* *}$ \\
Contato intimo & $16,0 \%(24)$ & $21,0 \%(30)$ \\
Transfusão & $11,3 \%(17)$ & $5,6 \%(08)$ \\
Ferimento acidente trabalho & $0,7 \%(01)$ & $72,5 \%(103)^{* *}$ \\
\hline Total & 150 & 142 \\
\hline
\end{tabular}

$* \mathrm{p}<0,10$

$* * \mathrm{p}<0,001$

Não houve diferença significativa entre grupos controle e de risco quanto à presença de contato intimo com portadores de hepatite ( $16 \%$ e $21 \%$, respectivamente) ou de história de transfusāo $(11,3 \%$ e $5,6 \%$, respectivamente). Mas, é bastante significativa a diferença quando comparamos o índice de ferimentos acidentais com material contaminado no ambiente de trabalho, que se mostrou nitidamente superior no grupo de risco $(72,4 \%)$ em relação ao controle $(0,7 \%)$.
História passada de hepatite foi mais freqüente entre os grupos de risco, assim como a prevalència dos indices de infecção pelo virus $B$, embora sem significância estatística $(26,8 \% \times 17,3 \%)$, com $\mathrm{p}<0,10$.

A análise de dados como uso de álcool tornou-se irrelevante, devido não só à precariedade da forma como o dado foi coletado, como à ausência de correlação com índice de infecção acumulada. 
Coelho HSM, Artemenko SRT, Martins CN, Carvalho DM, Valente J, Rodrigues EC, Alves LS, Martins MLM. Prevalência da infecção pelo virus $B$ na comunidade hospitalar. Revista da Sociedade Brasileira de Medicina Tropical 23:71-76, abr-jun, 1990

Não encontramos relação entre índices de doação de sangue e infeç̧ão pelo virus $B$ da hepatite.

$\mathrm{O}$ item cirurgia prévia não mostrou diferença significativa entre os vários grupos (controle $67 \%$ e risco $73 \%$ ), e não forneceu auxilio na discriminação de cirurgia com provável hemotransfusão.

A Tabela 2 mostra a prevalência de cada marcador viral testado, bem como o indice de infecção acumulada (que corresponde à presença de pelo menos um marcador viral).

Tabela 2 - Prevalência dos marcadores virais testados e da infeção acumulada nos diferentes grupos (\%).

\begin{tabular}{lccccccc}
\hline & & \multicolumn{7}{c}{ Risco } \\
\cline { 3 - 8 } & Controle & Total & Cirurgia & Enfermaria & Laboratório & Odontologia & Hemodiálise \\
\hline Número & 150 & 142 & 30 & 30 & 30 & 30 & 22 \\
HBsAg & 1,3 & 1,4 & zero & zero & 6,7 & zero & zero \\
AntiHBc & 14,7 & 21,8 & 33,3 & 13,3 & 16,7 & 20,0 & 27,3 \\
AntiHBs & 18,0 & 21,1 & 36,7 & 6,7 & 13,3 & 20,0 & 31,8 \\
Infeç̧ão Acumulada & 17,3 & 26,8 & 40,0 & 13,3 & 23,3 & 23,3 & 36,4 \\
\hline
\end{tabular}

Analisando em separado os subgrupos de risco, pudemos observar maiores indices de infecção acumulada entre cirurgiōes e profissionais de hemodiálise onde é maior a incidência de ferimentos acidentais no trabalho. Ambos os grupos mostraram prevalência significativa em relação ao grupo controle $(\mathrm{p}<0,01)$.

A Tabela 3 mostra os aspectos epidemiológicos e sua relação com infecção pelo vírus entre os diversos subgrupos.

Tabela 3 - Distribuição dos parâmetros pesquisados nos subgrupos de risco.

\begin{tabular}{lccccc}
\hline Parâmetros & Cirurgia & Enfermaria & Laboratório & Odontologia & Hemodiálise \\
\hline Idade média & 40,9 & 34,1 & 35,6 & 37,9 & 33,3 \\
Sexo masculino & $93,3 \%(28)$ & $10,0 \%(3)$ & $20,0 \%(6)$ & $80,0 \%(24)$ & $36,4 \%(8)$ \\
Infeção acumulada & $40,0 \%(12)^{*}$ & $13,3 \%(4)$ & $23,3 \%(7)$ & $23,3 \%(7)$ & $36,4 \%(8)^{*}$ \\
Tempo ocupação (méd.) & 8,9 anos & 5,2 anos & 7,0 anos & 11,2 anos & 5,9 anos \\
História passada hepatite & $13,3 \%(4)$ & $3,3 \%(1)$ & $13,3 \%(4)$ & $30,0 \%(9)$ & $13,6 \%(3)$ \\
Contato intimo & $23,3 \%(7)$ & $23,3 \%(7)$ & $30,0 \%(9)$ & $13,3 \%(4)$ & $13,6 \%(3)$ \\
Transfusão & zero & $10,0 \%(3)$ & $6,7 \%(2)$ & $6,7 \%(2)$ & $4,5 \%(1)$ \\
Ferimento acidente & $93,3 \%(28)^{*}$ & $53,3 \%(16)$ & $56,7 \%(17)$ & $83,3 \%(25)^{*}$ & $77,3 \%(17)^{*}$ \\
\hline Total & 30 & 30 & 30 & 30 & 30 \\
\hline
\end{tabular}

* $\mathrm{p}<0,05$ em relação ao grupo controle.

Entre parênteses está indicado o n. de casos positivos.

Ainda entre esses subgrupos, observamos a ausência de influência de outras formas de transmissão, como transfusão e contato com cônjuge portador da doença.

Tabela 4 - Proporçâo de infectados pelo virus $B$ de acordo com a faixa etária nos diversos subgrupos (\%).
Notamos relação direta da infecção pelo virus B com a idade, bem como com o tempo de atuação profissional, havendo duplicação dos índices de infecção acumulada quando o tempo de ocupação ultrapassa os dez anos (Tabelas 4 e 5).

\begin{tabular}{cccccccc}
\hline Grupos & \multicolumn{9}{c}{ Risco } \\
\cline { 2 - 7 } Idade & Controle & Total & Cirurgia & Enfermaria & Laboratório & Odontologia & Hemodiálise \\
\hline 19 a 24 anos & 22,2 & zero & zero & zero & zero & zero & zero \\
& $(2 / 9)$ & $(0 / 7)$ & - & $(0 / 3)$ & $(0 / 3)$ & - & $(0 / 1)$ \\
25 a 34 anos & 4,7 & 22,4 & 30,0 & 17,3 & 14,3 & 26,7 & 33,3
\end{tabular}


Coelho HSM, Artemenko SRT, Martins CN, Carvalho DM, Valente J, Rodrigues EC, Alves LS, Martins MLM. Prevalência da infeç̧ão pelo virus $B$ na comunidade hospitalar. Revista da Sociedade Brasileira de Medicina Tropical 23:71-76, abr-jun, 1990

(Continuação)

\begin{tabular}{|c|c|c|c|c|c|c|c|}
\hline \multirow[b]{2}{*}{ Idade } & \multicolumn{7}{|c|}{ Risco (\%) } \\
\hline & Controle & Total & Cirurgia & Enfermaria & Laboratório & Odontologia & Hemodiálise \\
\hline & $(3 / 64)$ & $(15 / 67)$ & $(3 / 10)$ & $(2 / 16)$ & $(2 / 14)$ & $(4 / 15)$ & $(4 / 12)$ \\
\hline 35 a 44 anos & $\begin{array}{c}25,5 \\
(11 / 43)\end{array}$ & $\begin{array}{c}28,9 \\
(13 / 45)\end{array}$ & $\begin{array}{c}33,3 \\
(4 / 12)\end{array}$ & $\begin{array}{c}14,3 \\
(1 / 7)\end{array}$ & $\begin{array}{l}25,0 \\
(2 / 8)\end{array}$ & $\begin{array}{c}20,0 \\
(2 / 10)\end{array}$ & $\begin{array}{l}50,0 \\
(4 / 8)\end{array}$ \\
\hline 45 a 54 anos & $\begin{array}{l}18,2 \\
(4 / 22)\end{array}$ & $\begin{array}{c}46,2 \\
(6 / 13)\end{array}$ & $\begin{array}{l}50,0 \\
(2 / 4)\end{array}$ & $\begin{array}{l}33,3 \\
(1 / 3)\end{array}$ & $\begin{array}{l}66,7 \\
(2 / 3)\end{array}$ & $\begin{array}{l}50,0 \\
(1 / 2)\end{array}$ & $\begin{array}{l}\text { zero } \\
(0 / 1)\end{array}$ \\
\hline 55 anos & $\begin{array}{l}50,0 \\
(6 / 12)\end{array}$ & $\begin{array}{l}40,0 \\
(4 / 10)\end{array}$ & $\begin{array}{c}75,0 \\
(3 / 4)\end{array}$ & $\begin{array}{c}\text { zero } \\
(0 / 1)\end{array}$ & $\begin{array}{c}50,0 \\
(1 / 2)\end{array}$ & $\begin{array}{c}\text { zero } \\
(0 / 3)\end{array}$ & $\begin{array}{c}\text { zero } \\
-\end{array}$ \\
\hline
\end{tabular}

Tabela 5 - Proporção de infectados pelo vírus $B$ de acordo com o tempo de ocupação (\%).

\begin{tabular}{|c|c|c|c|c|c|c|c|}
\hline \multirow[t]{2}{*}{ Grupos } & \multicolumn{7}{|c|}{ Risco } \\
\hline & Controle & Total & Cirurgia & Enfermaria & Laboratório & Odontologia & Hematologia \\
\hline 5 anos & $\begin{array}{l}13,3 \\
(4 / 30)\end{array}$ & $\begin{array}{l}13,3 \\
(2 / 15)\end{array}$ & $\begin{array}{c}\text { zero } \\
-\end{array}$ & $\begin{array}{l}25,0 \\
(1 / 4)\end{array}$ & $\begin{array}{c}\text { zero } \\
(0 / 5)\end{array}$ & $\begin{array}{c}\text { zero } \\
-\end{array}$ & $\begin{array}{l}16,7 \\
(1 / 6)\end{array}$ \\
\hline 5 a 10 anos & $\begin{array}{c}19,3 \\
(22 / 114)\end{array}$ & $\begin{array}{c}18,7 \\
(14 / 75)\end{array}$ & $\begin{array}{l}25,0 \\
(2 / 8)\end{array}$ & $\begin{array}{c}9,1 \\
(2 / 22)\end{array}$ & $\begin{array}{c}20,0 \\
(3 / 15)\end{array}$ & $\begin{array}{c}11,7 \\
(2 / 17)\end{array}$ & $\begin{array}{c}38,5 \\
(5 / 13)\end{array}$ \\
\hline 10 anos & $\begin{array}{c}\text { zero } \\
(0 / 6)\end{array}$ & $\begin{array}{c}42,3 \\
(22 / 52)\end{array}$ & $\begin{array}{c}45,5 \\
(10 / 22)\end{array}$ & $\begin{array}{l}25,0 \\
(1 / 4)\end{array}$ & $\begin{array}{c}40,0 \\
(4 / 10)\end{array}$ & $\begin{array}{c}38,5 \\
(5 / 13)\end{array}$ & $\begin{array}{l}66,7 \\
(2 / 3)\end{array}$ \\
\hline
\end{tabular}

\section{DISCUSSÃO}

Diversos estudos em outros paises vèm demonstrando aumento da prevalência de infecção pelo vírus $B$ entre profissionais de saúde avaliado através de pesquisa do HBsAg e AntiHBs 310121517 .

Esta prevalência chega a alcançar niveis 4 a 5 vezes maiores que controles em individuos que trabalham em setores de hemodiálise e técnicos de laboratório e bioquímicos, como nos mostra Gupta 11 . Outros grupos profissionais, como médicos, dentistas de especialidades cirúrgicas e enfermeiras de unidades de alto risco, também são considerados como de risco. Alguns profissionais que trabalham em hospitais em serviços de limpeza e transporte de sangue, também mostram alta prevalência de marcadores de infecção presente e passada $(26 \%$ e $43 \%$ respectivamente, com controles entre 5 e $7 \%)^{15} 17$.

É interessante assinalar aqui, que nos estudos por nós consultados, houve diferenças na conceituação de controle, ora sendo utilizados doadores de sangue, ora população não hospitalar escolhida ao acaso. Em nosso estudo, utilizamos como controle técnico em administração e secretários do setor de ensino, fora do contato com pacientes do hospital e encontramos prevalência de infeç̧ão acumulada de
$17,3 \%$ com o uso de três marcadores virais ( $\mathrm{HBsAg}$, AntiHBc e AntiHBs). Doadores de sangue do nosso hospital apresentaram uma taxa cumulativa de infecção próxima de $20 \%$, que não difere estatisticamente de nossos controles.

Encontramos uma prevalência de infecção cumulativa pelo virus $B$ maior entre profissionais de saúde $(26,8 \%)$ que entre o controle $(17,3 \%)$, porém sem significância estatística $(p<0,1)$.

Quando estudamos o grupo de profissionais de saúde de acordo com a função exercida, observamos que os cirurgiões e os profissionais que trabalham em hemodiálise apresentam alta taxa de prevalência, alcançando $40 \%$ e $36,4 \%$ respectivamente, com significância estatística em relação aos controles $(\mathbf{p}<0,05)$.

Esses subgrupos apresentaram no questionário aplicado um indice bastante elevado de ferimentos acidentais no trabalho, chegando a $93,3 \%$ entre os cirurgiões e $77 \%$ entre os profissionais de hemodiálise, comparado a apenas $0,7 \%$ entre os controles. Outros dados da história passada como cirurgia previa, transfusões e contato íntimo com portadores de hepatite, não foram relevantes quando comparados aos controles. 
Considerando que os ferimentos em campo cirúrgico são acidentes e não preveníveis com luvas ou educação para uso de material protetor, acreditamos que a profilaxia pré-exposição com vacinas seja o único método efícaz ${ }^{4} 13$.

Entre os dentistas encontramos uma prevalência intermediária entre as do controle e a dos grupos de maior risco, apesar de submetidos ao fator de risco (ferimento acidental) com freqüência alta $(83,3 \%)$. Talvez, isto se deva ao tipo de especialidade odontológica exercida, e à freqüencia com que ocorram ferimentos (o que é dificil de quantificar numa entrevista).

Fatores como idade e tempo de atividade profissional têm sido relatados na literatura como dados que influenciam na prevalência de populaçōes estudadas ${ }^{5}$ 15. Em nosso trabalho, o grupo controle e o grupo de risco tiveram médias de idade e de tempo de ocupação comparáveis. Quando analisamos a prevalência de infecção cumulativa entre os controles e os diversos subgrupos, em relação à faixa etária, observamos um nítido aumento da prevalência em todos os grupos à medida que aumenta a idade. Quando consideramos todas as pessoas estudadas, independente do fator de risco, observamos entre os extremos etários, ou seja, naqueles com menos de 25 anos e nos com mais de 55 anos, prevalências de $12,5 \%$ e $45,4 \%$, respectivamente; isto significa uma prevalència quase 4 vezes maior.

$O$ fator idade não influenciou as conclusões de nosso trabalho em termos comparativos entre os grupos.

O tempo de ocupação é uma variável considerada importante na prevalência de infecção pelo vírus $B$, pois aumenta o risco de exposição aos materiais contaminados. O tempo médio de ocupação profissional foi semelhante entre os grupos controle e de risco (7,5 e 7,8 anos, respectivamente).

Quando analisamos o tempo de ocupação em relação à prevalência cumulativa, observamos que os subgrupos de risco mostram um crescimento progressivo da prevalência, principalmente entre aqueles com mais de 10 anos. de atividade profissional. Existem grupos, como por exemplo a hemodiálise, em que a prevalência aumenta de $16,7 \%$ entre aqueles com menos de 5 anos de atividade, para 66,7 naqueles com mais de 10 anos de profissão.

Este fato é da máxima importância nos programas de vacinação, já que o fato de não encontrarmos uma prevalência elevada numa determinada área, estudando exclusivamente pacientes jovens, com pouca experiência profissional, pode subestimar a prevalência real do risco da atividade profissional daquele grupo. Assim, por exemplo, entre os técnicos de laboratório, nenhum profissional com menos de 5 anos de atividade tinha qualquer marcador de infecção pelo virus B. No entanto, naqueles com mais de 10 anos de profissão, a prevalência elevou-se para $40 \%$, indicando que este grupo deva ser também vacinado.

No nosso material, o subgrupo de enfermagem não mostrou diferenças importantes em relação ao controle, mesmo quando levamos em conta o tempo de atividade profissional. É bem possivel que tenhamos estudado um número muito pequeno de profissionais em relação ao seu universo dentro do hospital e, esta amostra não seja significativa do que realmente se passa com o grupo.

Importante também assinalar que os estudos epidemiológicos devem correlacionar a prevalência de infecção com a atividade profíssional, e não com a área de trabalho (p. ex.: CTI, emergência, etc).

Isto dificulta a comparação de nosso estudo com aquele de Castro e cols realizado também no Rio de Janeiro, onde foram encontrados niveis elevados de infecção presente ou passada entre profissionais que trabalham na lavanderia, hemodiálise, centro cirúrgico e unidade de emergência ${ }^{2}$. Acreditamos que a análise dos dados referentes à prevalência torna-se dificultada, pois no mesmo local, como por exemplo a emergência, trabalham profissionais em atividades diversas, e portanto de riscos diferentes.

Podemos observar que há maior prevalência de infecção passada pelo vírus $B$ da hepatite entre profissionais de saúde em relação a controles do nosso hospital, e que entre profissionais de saúde, aqueles com história de ferimentos acidentais no trabalho apresentam índices significativamente maiores de infecção passada que os controles com $p<0,05$.

Além disso, o tempo de atividade profissional aumentou a prevalência de infecção pelo vírus B nos grupos estudados. É da máxima importância que conheçamos a prevalência entre faixas de tempo de trabalho diferentes, a fim de que possamos analisar a indicação de vacinação nos grupos estudados.

Nossos resultados indicam que a vacinação contra a Hepatite B deve ser efetivada precocemente entre os cirurgiōes e profissionais de hemodiálise, pelo risco de contaminação no trabalho, bem como para os técnicos de laboratório e dentistas em função do aumento da prevalência com o tempo de atividade profissional.

\section{SUMMARY}

The authors studied the prevalence of $\mathrm{HBV}$ markers among health care personnel of the University Hospital of the Federal University of Rio de Janeiro. The aim of study was to identify the high risk groups, in order to counsel vaccination of those groups at risk as a routine. As a control group, a 
group of office workers of the hospital were chosen. A significant difference of incidence of $H B V$ markers, mainly in surgeons (40\%) and hemodialysis unit personnel $(36.4 \%)$ when compared to the control group, was observed $(p<0.05)$. The incidence increased with age and the time spent in the profession. The authors concluded that vaccination is indicated in surgeons hemodialy sis personnel, dentists and laboratory personnel.

\section{Key-words: Hepatitis B. Health care personnel.}

\section{REFERÊNCIAS BIBLIOGRÁFICAS}

1. Brandão Mello $\mathrm{CE}$, Oliveira CAB, Fialho $F$, Gonzaga AL, Mello AS. Hepatite e SIDA. Moderna Hepatologia 1:1-11, 1986.

2. Castro EJ, Rosa Filho SM. Programa de detecçào de marcadores do virus $B$ da hepatite em equipes hospitalares de alto risco. Skopia Médica 5:18-22, 1987.

3. De Franchis R, Vecchi M, Primignani M, De Vecchi A, Porzia RM, Fontana MC, Monforte AD. Prevalenza do HBsAg e AntiHBs nel personale ospidaliero. Bollttino Dell'Instituto Sieroterapico Milanese 61:151-157, 1982.

4. Dienstag JL. Toward the control of hepatitis B. The New England Journal of Medicine 303:874-876, 1980.

5. Dienstag JL, Ryjan DM. Occupational exposure to hepatitis B virus in hospital personnel: infection or immunization? American Journal of Epidemiology 115:26-39, 1982.

6. Figueiredo Mendes T. Vacina contra hepatite B. Moderna Hepatologia 1:9-11, 1983.

7. Figueiredo Mendes T. Um século de virus B. Moderna Hepatologia 1:1-6, 1984.

8. Figueiredo Mendes T, Pittella AMM, Torres PRR, Méxas PPF, Simonetti SRR, Schatzmayn HG, Herbert BA, Vasconcelos MCL, Hepatite B em doadores de sangue. Medicina de Hoje 1:368-377, 1981.

9. Figueiredo Mendes T, Stephan da Cruz PR, Pittella AMM, Méxas PPF, Podkameni W, Herbert B. Transmissão sexual do virus da hepatite B. Moderna Hepatologia 3:1-6, 1982.
10. Garibaldi RA, Forrest JN, Bryan JA, Hanson BF, Dismukes, WE. Haemodialysis - associated hepatitis. Journal of the American Medical Association (JAMA) 225:384-386, 1973.

11. Gupta M. Recherches sur le pouvoir pathogène du virus de l'hépatite B. T' èses, Sciencies Biologiques, Bordeaux, 20p., 1976.

12. Janzen J, Tripatris I, Wagner W, Schliter M, MullerDethers E, Wolters E. Epidemiology of hepatitis B surface antigen (HBsAg) and antibody to $\mathrm{HBsAg}$ in hospital personnel. The Journal of Infectious Diseases 137:261-265, 1978.

13. Maynard JE. Hepatitis B vaccine: strategies for the utilization. Inser Symposium 18:13, 1981.

14. Okochi K, Murakami S, Ninomiya K, Kaneko M. Australia antigen transfusion and hepatitis. Vox Sanguinis 18:289-300, 1970.

15. Saraux JL, Buffet C, Etienne JP, Hépatite virale B chez le personnel de santé. La Press Médicale 14:971-975, 1985.

16. Seef LB, Wright EC, Zimmerman HJ. A cooperative study of post-transfusion hepatitis, 1960-1974. Incidence and characteristics of hepatitis and responsible risk factors. American Journal of the Medical Sciences 270:355-362, 1975.

17. Smith JL, Maynard JE, Berquist KR, Doto IL, Webster HM, Sheller MJ. From the Center for Disease ControlComparative risk of hepatitis B among physicians and dentists. The Journal of Infectious Diseases 133:705$706,1976$.

18. Stevens CE, Beasley RP, Tsui J, Lee W. Vertical transmission of hepatitis B antigen in Taiwan. The New England Journal of Medicine 292:771-774, 1975.

19. Szmuness W, Harley EJ, Kafeez J, Cladd ES. Sociodemographic aspects of the epidemiology of hepatitis B; viral hepatitis. The Franklin Institute Press, p. 297, 1978.

20. Szmuness E, Prince AM, Brotman B, Hirsch RL. Hepatitis B antigen and antibody in blood donors: an epidemiologic study. Journal of Infectious Diseases 127:17-25, 1973.

21. Villarejos VM, Visona KA, Gutierrez A, Rodrigues A. Role of salive, urine and feces in the transmission of type B hepatitis. The New England Journal of Medicine 291:1375-1378, 1974. 